\title{
Further Note on Metallographical Study on Galvanized Steel.
}

By Constructor Lieutenant-Commander, Y. Taji, I. J. N., Member.

LRead at the Meeting of the Society of Naval Architects of Japan,

in Autumn of 1922.]

The present note is a supplement to a paper on "Metallographical Study on Galvanised Steel" which the writer had the honour of reading before the meeting of this society on 15th., Nov., 1918. The earnest request from some of our fellow-members during discussion time was to deal with galvanizing methods other than the hot process, but the writer having since been extremely busy, the submission of this note has been regrettably delayed.

Here, only the "Sherardizing method" is dealt with, which is very popular now-adays and will be more interesting to casual readers.

\section{Selection of Test Pieces.}

Test pieces were first selected from popular articles such as bolts, nuts, wcod screws, small rivets, small angle bars, trough rests, etc., which were submitted to the Admiralty from the makers for the adoption of the process.

Descriptions for the test pieces are as follows:- 


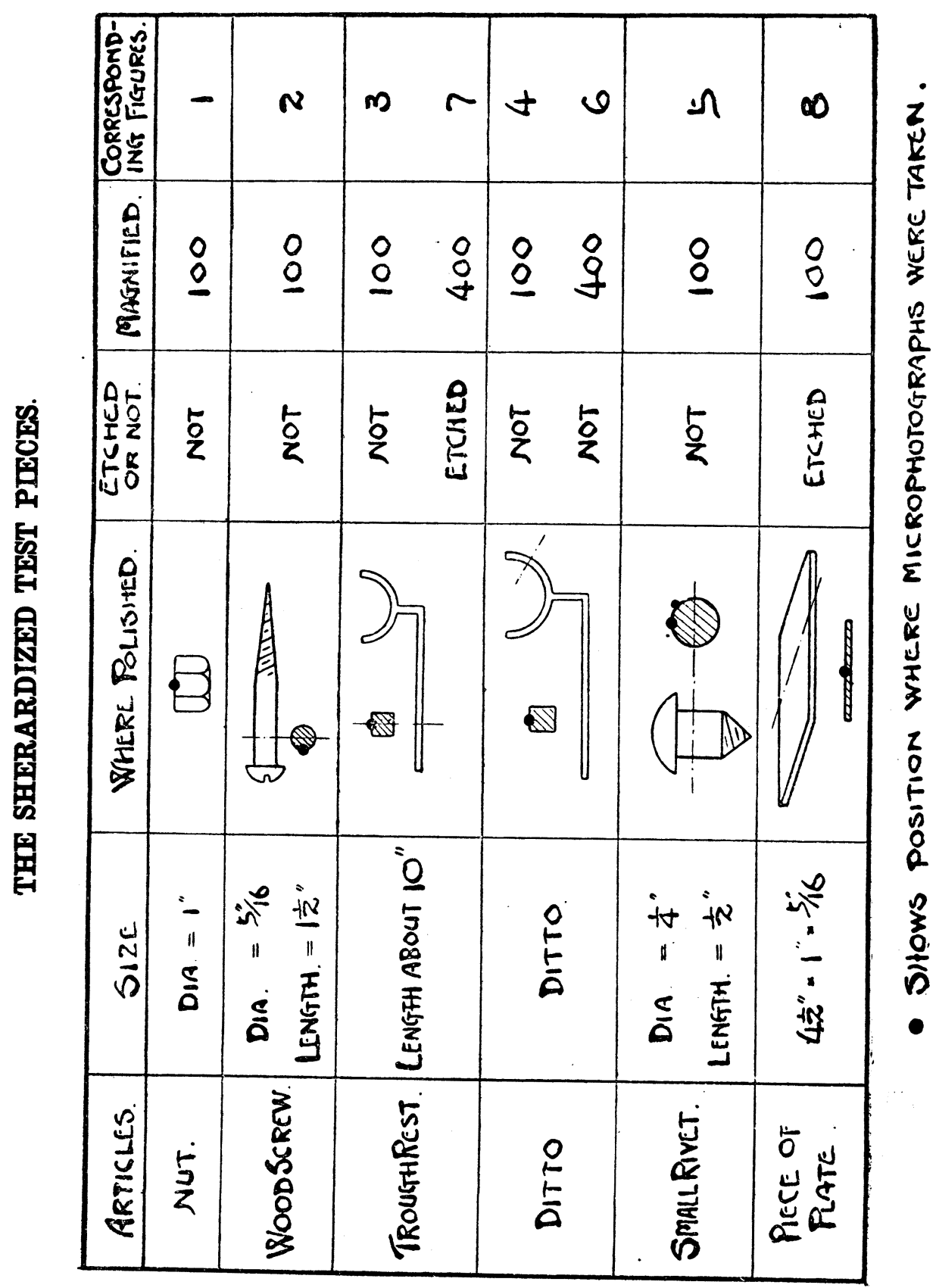


To investigate the effect of time on the formation of the coating, some wellsherardized test pieces of mild steel treated by the same process for different durations were supplied by the makers.

\section{General Feature of the Microstructure of Sherardized Coating.}

Investigations upon the construction of the coating of actually sherardized materials such as bolts, nuts, wood screws, etc., are extremely difficult on account of the thinness of the coating. Only typical structures will be seen from the sherardized steel trough rest and the rectangular steel plates, specially sherardized for the purpose.

Figs. 4 and 6,3 and 7,14 and 15, 16 and 17 give some of the typical structures.

In this mode of construction, the recognition of three layers such as ' $a$ ', ' $b$ ', and ' $c$ ', as explained before in cases of the hot galvanizing process, is not possible.* The whole coating appears more or less as of single structure corresponding to ' a' layer of hot galvanised coating, althoủgh some grade of iron contents due to variation of distance from the steel surface may be partially observed.

The whole layer is very hard and its direction of crystallization appears to be generally perpendicular to the steel surface. The layer is evidently an iron-zinc alloy with not more than $5 \%$ of iron, and possibly made up from a great part of ' $n$ ' crystals (consisting of $\mathrm{FeZn}_{3}$ and $\mathrm{FeZn}_{7}$ ) and a smaller part of ' $\mathrm{m}$ ' crystals (consisting of different dispositions of $\mathrm{FeZn}_{3}$ and $\mathrm{Fe}_{7}$ ). The layer itself is therefore hard and brittle, so that to polish a section for microphotographical investigation was not an easy matter on account of the separation of the layers into numerous parts during the operation.

The hardness of the coating may also be easily recognised by scratching the surface with a pen-knife; this of course proves the surface of sherardized material is able to take a very high polish.

The very dark layer extremely near to the steel surface may be considered as only due to some impurities and roughness on the surface, and this aftords more freedom for crystallization than a smooth surface, so that the structure thereabouts sometimes tends to become granular. The whole layer, however, cannot be distinguished into three layers 
as in cases of the hot process, but may be considered as only possessing the difference of shades due to a very slight difference of the iron content.

'The thickness of the sherardized coating in wood screws, small rivets, etc., is less than $0.01 \mathrm{~mm}$; even in specially well-sherardized materials the thickness is not more than $0.05 \mathrm{~mm}$. in ordinary practice, while by the hot galvanized process in ordinary cases it is nearly $0.16 \mathrm{~mm}$.*

\section{Effect of Time of Sherardizing on the Formation of Layers.}

Four small rectangular steel plates 2 inches by 1 inch with $\frac{1}{4}$ inch thickness were specially sherardized by the makers after treatments for 30 minutes, one hour, two hours, and four hours.

Microstructure of these samples are shown in Figs. 10. to 17.

The properties of the structure are more or less similar to those already explained. In each case, although the nearer to the steel surface the higher is the iron content, we cannot distinguish the boundaries of layers as in the case of the hot process.

The thickness of coating increases naturally with the time of sherardizing. The coating after 30 minutes treatment is so thin as to be easily attacked by an oxidising agent. Even after one or two hours treatment, their thickness is much less than that by the hot process. Four hours exposure in the sherardizing apparatus alone will give a reasonable thickness corresponding to a well-galvanized coating by the hot process.

\section{Comparison of Coatings Produced by Sherardizing Method and Hot Galvanized Process.}

(a) Structural Difference.

The coating produced by the hot process has generally three distinct layers. The nearest to the steel surface is an extremely hard zinc-iron alloy, the middle layer is a less hard zinc-iron alloy and the outer one is an entirely soft zinc layer or with

\footnotetext{
* See Fig 9.
} 
possibly a slight trace of iron. Therefore, the surface is generally soft, easily scratched by a pen-knife and not able to take a high polish.

The coating produced by the Sherardizing method generally consists of a single layer with a slight difference of shade due to minute variations of the iron content and is a very hard zinc-iron alloy. Therefore, the surface is not easily scratched by a pen-knife, and when polished has a brilliant lustre.

The thickness of the coating due to the hot process is generally not very thin, while that of Sherardizing method is extremely thin except in some special cases. Therefore, articles coated by the Sherardizing method are rnore liable to be easily attacked by oxidising agents than are those coated by the hot process.

(b) Endurance in Sea Water.

To compare the endurance of sherardized and hot galvanized materials, three plates in each method as described below were selected.

\begin{tabular}{|c|c|c|c|c|c|}
\hline \multicolumn{3}{|c|}{ sherardized Materials } & \multicolumn{3}{|c|}{ Hot Galvanized Materials } \\
\hline Mark & Size & Hours Sherardized & Mark & Size & Hours galvanized \\
\hline A & $5 \frac{1^{\prime}}{2} \times 8^{\prime \prime} \times \frac{3}{16} 6^{\prime \prime}$ & $1 \frac{1}{2}$ hrs. & a & Same as A & 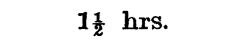 \\
\hline B & $5^{\prime \prime} \times 2^{\prime \prime} \times \frac{55^{\prime \prime}}{16}$ & $4 \mathrm{hrs}$. & b & Same as $B$ & $\begin{array}{l}\text { Thicker than } \\
\text { ordinary practice }\end{array}$ \\
\hline C & $4 \frac{1}{2}{ }^{\prime \prime} \times 1^{\prime \prime} \times \frac{\frac{\pi}{16}}{16}$ & 2 hrs. & e & Same as $\mathbf{C}$ & ordinary \\
\hline
\end{tabular}

These were left immersed in sea water near Yokosuka Docks for nearly one year.

After taking off all shells etc., the plates were carefully cleaned by fresh water. In this condition, many rusty spots were found on the surface of the sherardized materials, while there was no rust on the hot galvanized materials.

When the test pieces were immersed in diluted hydrochloric acid and cleaned with a wire brush, the trace of rust was more intensified in the sherardized materials. Formation of hydrogen bubbles was more noticeable in the hot galvanized plates.

Then the test pieces were kept for a while in concentrated hydrochloric acid until a very negligible amount of zinc-alloy coating was left, when the intensity of rust was much more significant in the sherardized plates.

The above results were exactly the same in the plates sherardized for four hours 
and it is said from general experience that the rusting of sherardized materials is much more rapid than in the case of hot galvanized ones.

(c) Conclusion.

From the foregoing results, we may conclude that the sherardized materials will be suitable for the inside fittings of ships and will have the advantage of being able to be polished brightly owing to the surface hardness, but where sea water attacks, they are more liable to become rusty, while the hot galvanized materials have more resistance as an anti-corrosive coating, although their outward appearance is not as pleasing as that of sherardized ones.

The writer desires to express heartfelt thanks to Ordnance Commander H. Kikkawa, I.J.N. and Constructor Lieutenant R. Watanabe, I.J.N. for their valuable help in the taking of photographs and assistance in carrying out the experiments.

5th., Oct., 1922. 
PL. I. a.

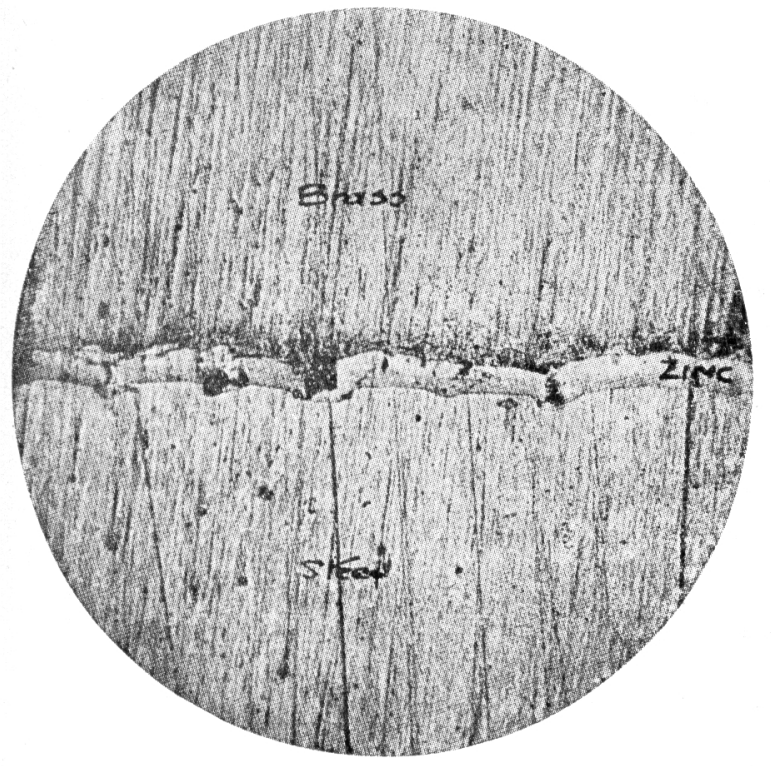

Fig. 1. Sherardized Nut. $\times \mathbf{1 0 0}$ Not etched.

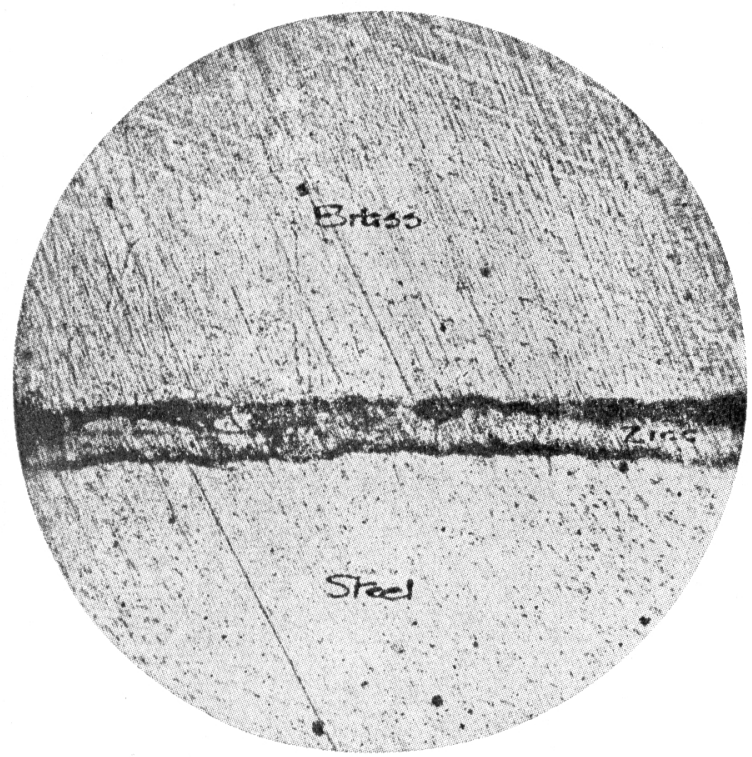

Fig. 3. Sherardized Trough Rest. $\times 100$ Not etched.

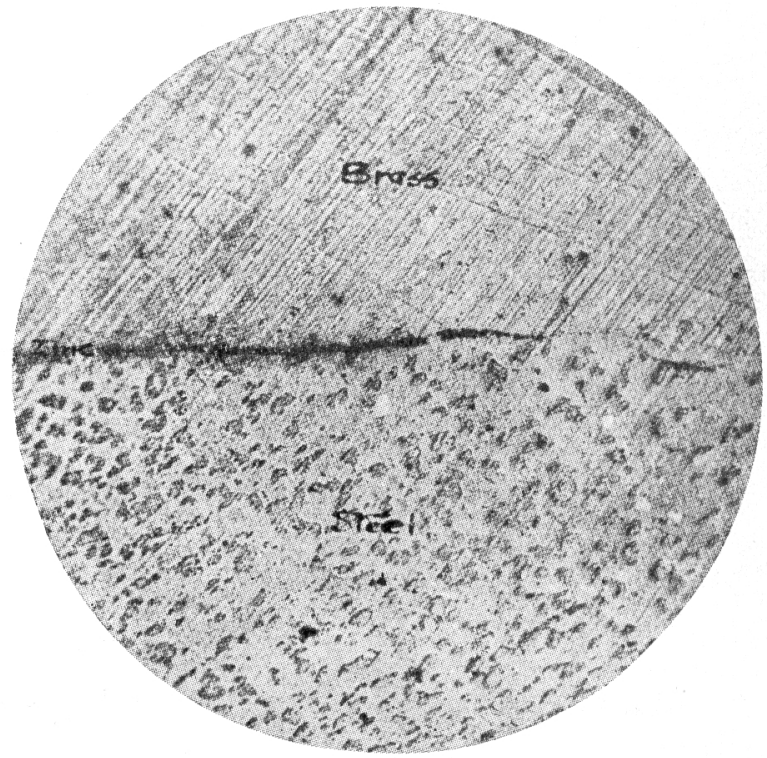

Fig. 2. Sherardized Screw $\times 100$ Not etched.

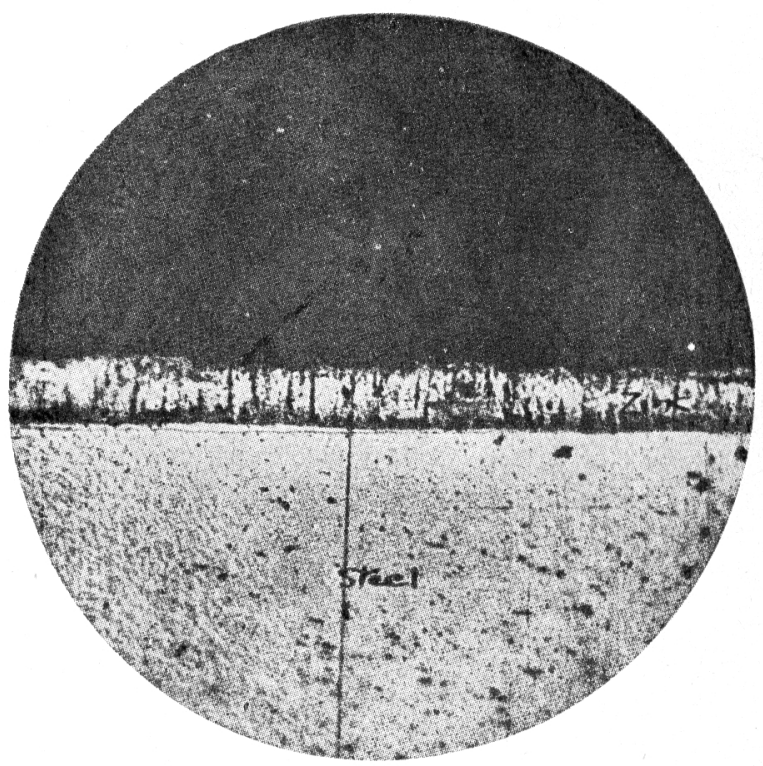

Fig. 4. Sherardized Trough Rest. $\times 100$ Not etched. 
PI. I b.

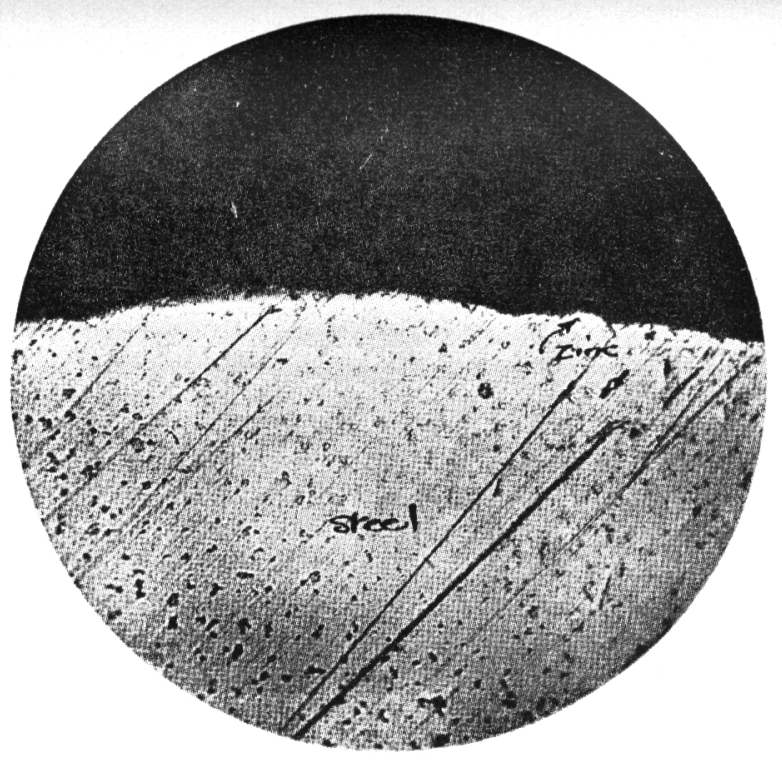

Fig. 5. Sherardized Rivet. $\times 100$ Not etched.

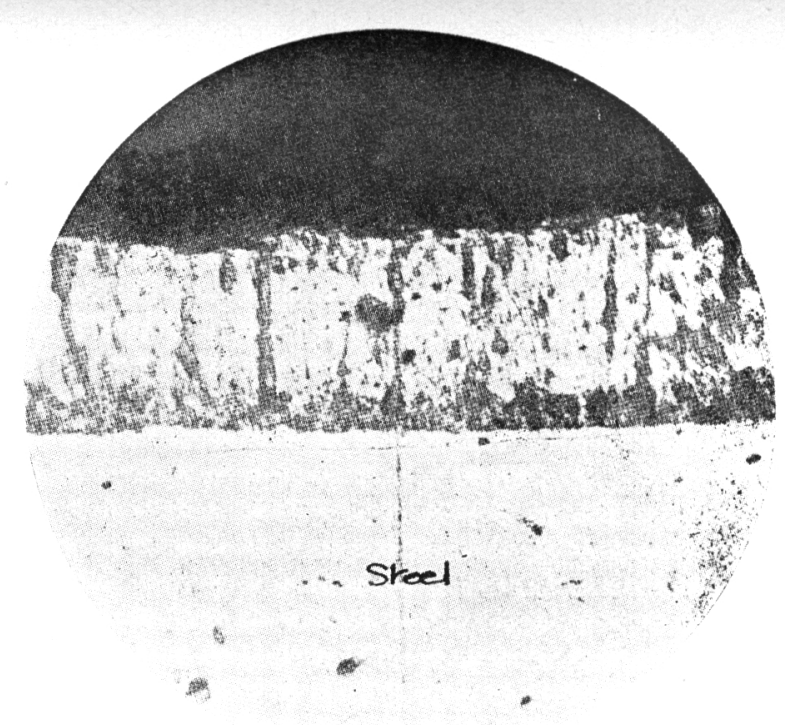

Fig. 6. Same as Fig. $4 . \times 400$ Not etched.

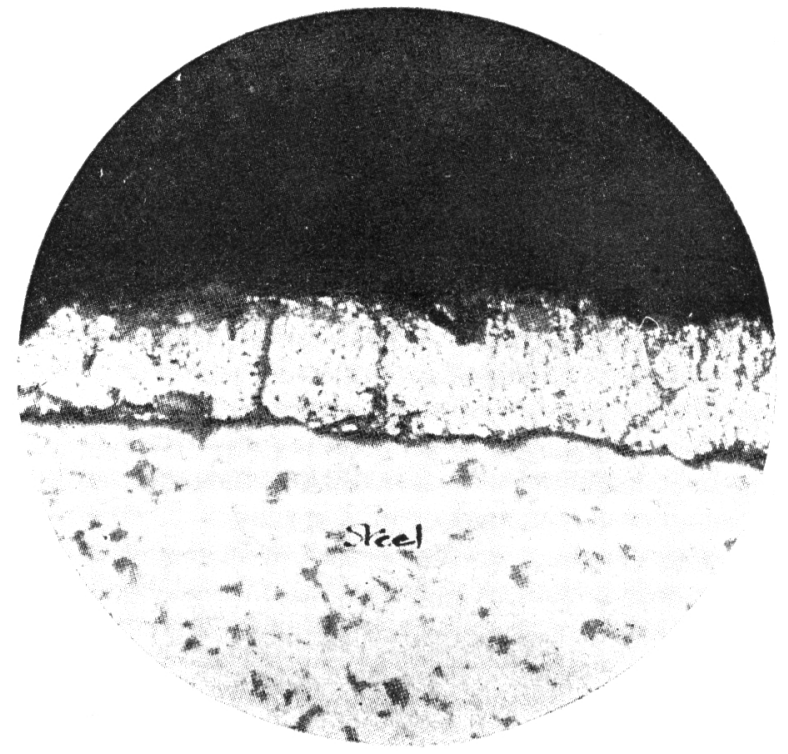

Fig. 7. Same as Fig. 3. $\times 400$

Etched.

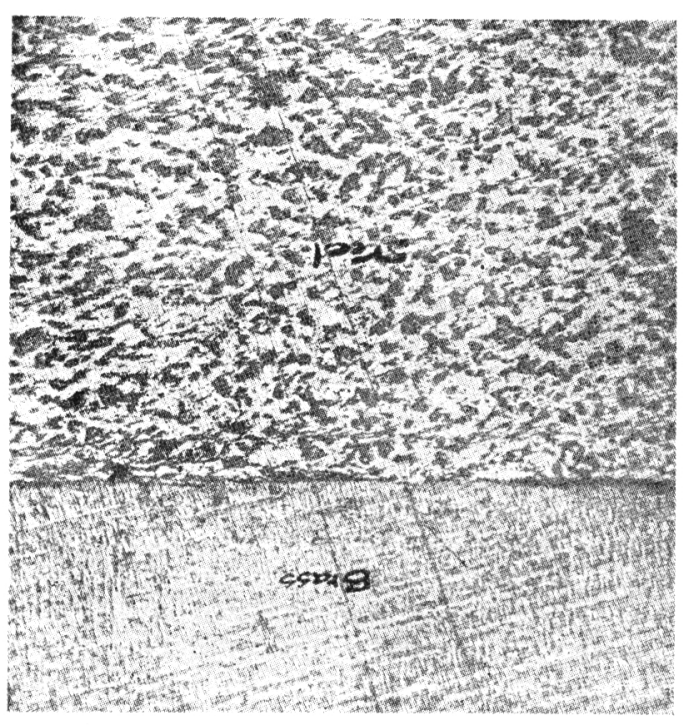

Fig. 8. Sherardized Plate. $\times 100$ Etched.

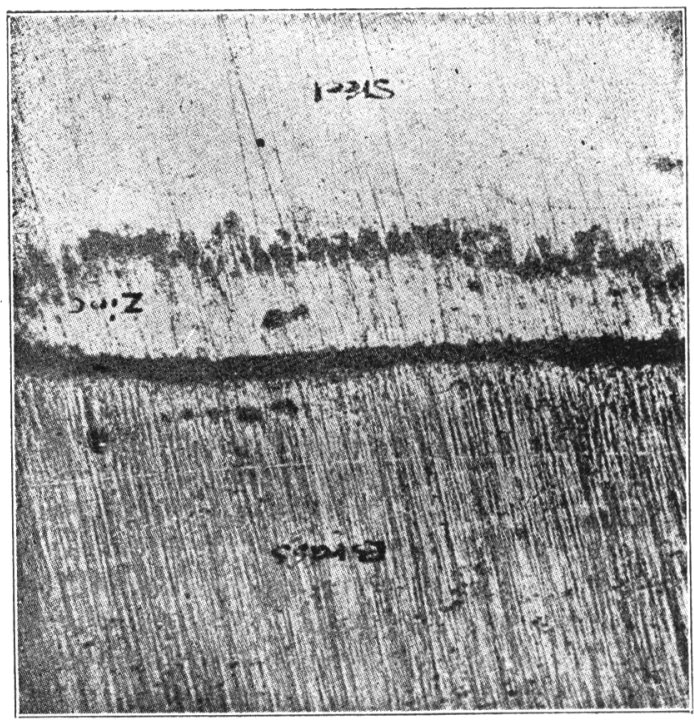

Fig. 9. Hot Galvanized Plate. $\times \mathbf{1 0 0}$ Not etched. 


\section{PL. II a.}

Effect of Time on Sherardized Materials All etched by Picric Acid.

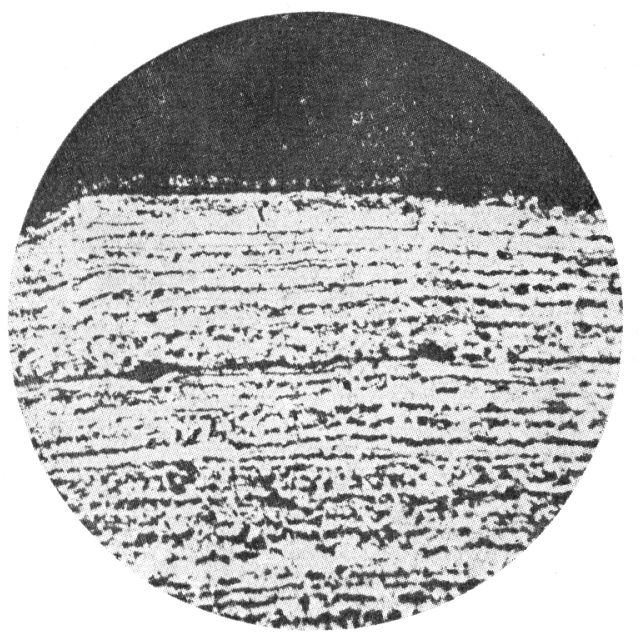

Fig. 10. 30 mins. $\times 100$.

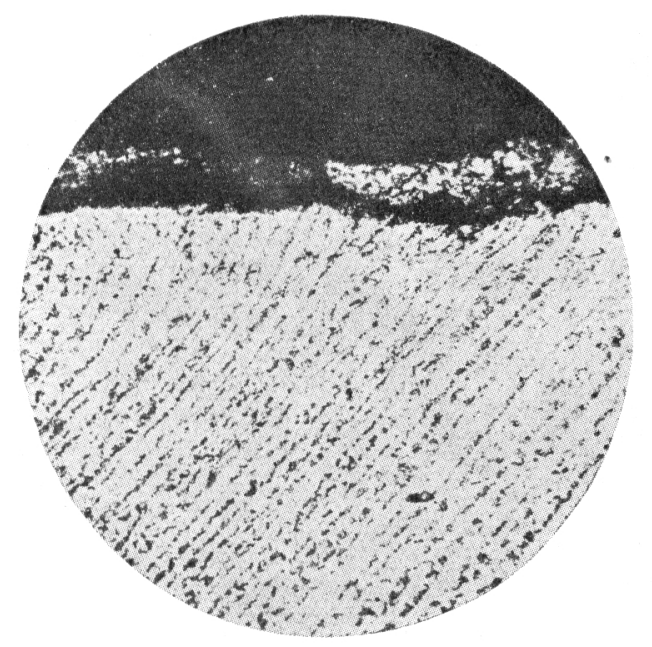

Fig. 12. 1 hour $\times 100$.

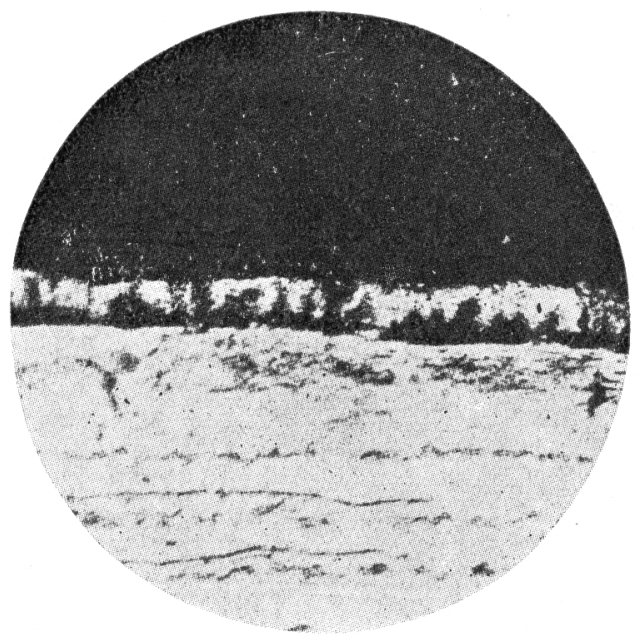

Fig. 11. 30 mins. $\times 400$.

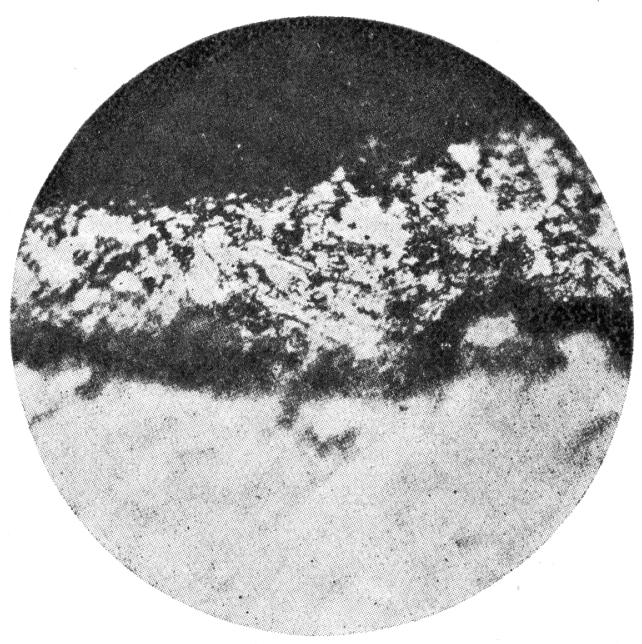

Fig. 13. 1 hour $\times 400$. 
PL. II b.

Effect of Time on Sherardized Materials All etched by Picric Acid.

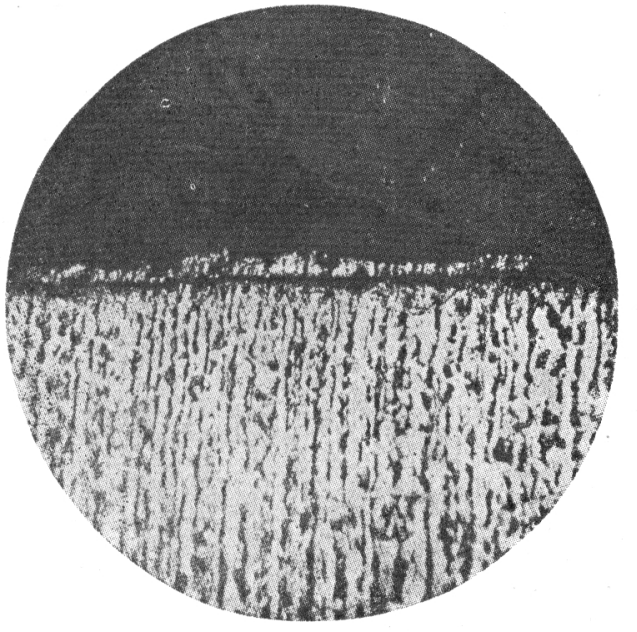

Fig. 14. 2 hours $\times 100$.

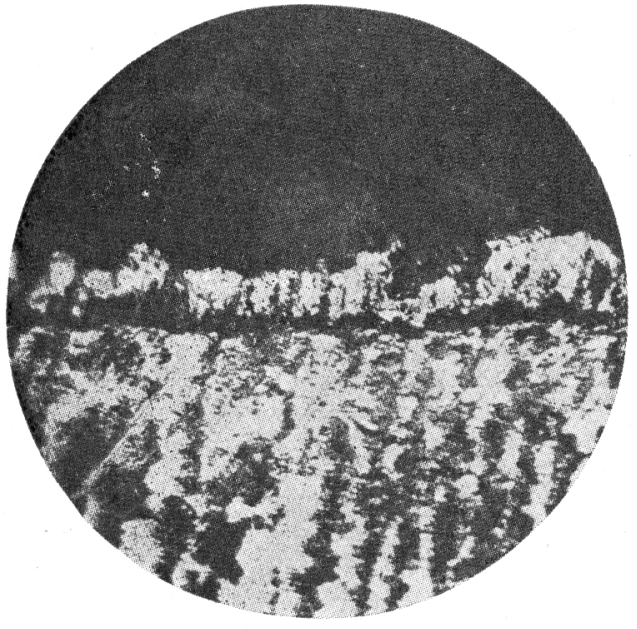

Fig. 15. 2 hours $\times 400$.

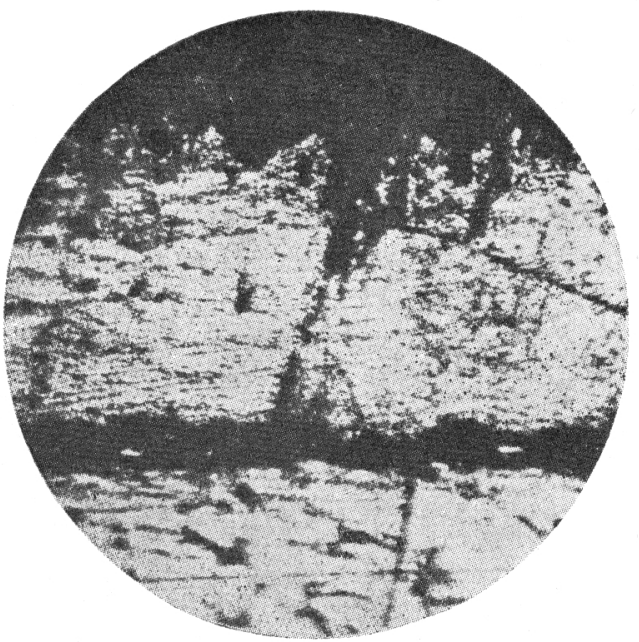

Fig. 17. 4 hours $\times 400$.
Fig. 16. 4 hours $\times 100$.

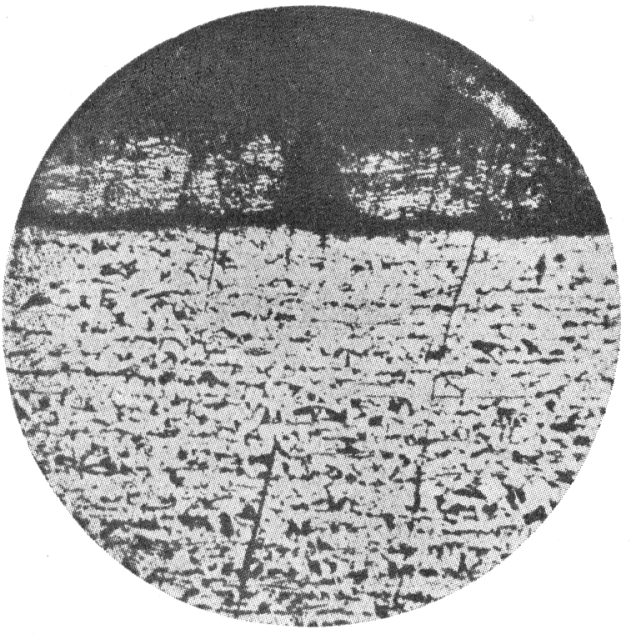

